\title{
PERCEPÇÃO AMBIENTAL NA GESTÃO DE RESÍDUOS SÓLIDOS: ESTUDO DE CASO NUM CLUBE DE CAMPO DE UMA CIDADE DO ESTADO DE SÃO PAULO
}

Raoni Duarte dos Santos ${ }^{1}$ Ismail Barra Nova de Melo²

Resumo: O problema dos resíduos sólidos e sua contínua busca por soluções adequadas de gestão a fim de minimizar danos ao Meio Ambiente, assim como a depredação do planeta na busca incessante por recursos estimulada por um consumismo crescente e ilimitado, aumenta diariamente. Este trabalho tem como objetivo diagnosticar a percepção ambiental dos trabalhadores de um Clube de Campo no interior do Estado de São Paulo a respeito da Gestão de Resíduos Sólidos. Trata-se de um estudo de caso no qual as informações foram obtidas por meio de entrevistas. Os resultados mostraram que parte dos funcionários do Clube não conhece as ações para a Gestão dos Resíduos Sólidos, no entanto, a maioria demonstrou interesse em contribuir com o programa, independentemente do grau de instrução.

Palavras-chave: Percepção Ambiental; Consumismo; Cidadania; Instituição Privada. 


\section{Introdução}

Nos tempos atuais, podemos observar o constante aumento na atenção recebida pelos problemas ambientais por parte da humanidade, tendo em vista a crise ecológica que a mesma vem enfrentando, principalmente após a Revolução Industrial no século XVIII e a consolidação do capitalismo que vieram a gerar uma maior demanda por recursos naturais e estimulo pelo consumo, pressionando ecossistemas e depredando o Planeta como um todo, ignorando fronteiras e suprimindo culturas e povos (GUERRA, 2012).

Santos (1985) coloca que, apesar de parecer insignificante, cada impacto gerado de forma individual traz suas diferenças relevantes para o meio, que como consequência acarretará em sua modificação. Mesmo sendo um fato isolado, ele pode ser replicado por outras pessoas, construindo assim uma escala geométrica, cabendo tal comparação também ao consumo. Cada pessoa retirada da linha da pobreza, aos olhos do mercado, não é menos um pobre, mas sim mais um consumidor em potencial.

A concepção de desenvolvimento mostra-se um tanto quanto perigosa, tendo em vista a deturpação de seu real significado e seu uso no meio econômico. Na lógica capitalista, desenvolver é dar condições de consumo para as populações e também para determinadas regiões receberem investimentos e infraestrutura que tem como objetivo atrair mais capital, onde $o$ "[...] desenvolvimento é central no processo de construção do que se convencionou chamar de Modernidade" (GONÇALVES, 1992, p.10). A modernidade é com certeza um fator muito positivo para a civilização humana incluindo seus avanços técnico-científicos e nas relações humanas, contudo, ela é construída e vendida como uma espécie de "portal dimensional" do novo e do mais moderno. É colocada de uma forma em que, caso você não se mantenha atualizado, adquirindo as últimas tendências ou aquilo que é mais apropriado para o momento, você será considerado um ser estranho no meio, e isolado do restante da humanidade que vive e respira a modernidade. O sentimento de não pertencer ou de ausência desse meio pode gerar em uma pessoa a chamada "morte social" (BAUMAN, 2008).

Gonçalves (1992), Rodrigues (1992) e Santos (2000), apontam para o poder da massificação e da globalização, acarretando em uma homogeneização cultural e supressão das individualidades; e é sempre muito bom frisar que individualidade e individualização são termos completamente diferentes e muitas vezes opostos de princípios. Tal fator evidencia o papel e função de cada ator na sociedade, e com uma cultura mais homogênea, aspectos de dominação e imposição de comportamentos são facilmente estabelecidos, principalmente pelo uso da mídia e dos meios de comunicação. Para Gonçalves (1992, p.9) "[...] qualquer sociedade humana institui uma ordem de significações, de normas, regras e valores, enfim institui um ethos que dá sentido a si mesma, às suas práticas". Mesmo que para nós, os rumos da humanidade não façam o menor sentido, os atores dominantes arrumam

revista brasileira educação ambiental 
meios e formas para legitimá-lo, mostrando para a maior parte da população que seus hábitos possuem um claro sentido (GONÇALVES, 1992).

Um desses meio que é grandemente e inteligentemente utilizado, é a propaganda, através de diversas campanhas de marketing. A propaganda, com seu caráter e personalidades mutáveis, atende às demandas e às necessidades do mercado, falando $o$ que as pessoas querem ouvir e direcionando para o tipo de consumo que é mais conveniente para o momento, formando dessa maneira, segundo Bauman (2008), uma "sociedade de consumidores" que se diferencia através de uma nova construção das relações humanas, a partir de um padrão, uma semelhança, das relações entre os consumidores e os seus objetos de consumo.

$\mathrm{Na}$ maioria das descrições, o mundo formado e sustentado pela sociedade de consumidores fica claramente dividido entre as coisas a serem escolhidas e os que as escolhem (BAUMAN, 2008). Entretanto, observa-se que "Na sociedade de consumidores, ninguém pode se tornar sujeito sem virar mercadoria" (BAUMAN, 2008, p.21), onde uma das características que mais se distingue das demais neste tipo de sociedade é justamente a transformação dos consumidores em mercadorias onde as campanhas publicitárias sempre procuraram um ponto a ser explorado tanto no produto ou serviço a ser oferecido quanto no consumidor. Geralmente aspectos que lidam com a vaidade, ou com a constante vontade do ser humano em tornar-se o centro das atenções ou de se diferenciar das massas, mostrando ser (através do ter) mais que o seu semelhante (ou concorrente?). Muitas vezes esse poder vem na forma de posses e bem materiais, que de certa forma, dá um pseudo poder a seu dono (BAUMAN, 2008).

O consumismo desenfreado, e seu consequente estímulo da competitividade entre as pessoas suprimem suas capacidades morais e intelectuais, além de reduzir sua personalidade (e também a individualidade) e sua visão do mundo, abrindo caminho para um esquecimento da oposição fundamental entre os papéis do consumidor e do cidadão. Ou seja, a visão de mundo (ou visão global), é aquela em que cada indivíduo tem noção de seus atos, possuindo plena consciência de que pode afetar outras pessoas e outros seres em diferentes regiões (SANTOS, 2000).

Como Santos (2000) já fez questão de frisar, as sociedades atuais (baseadas no consumo) costumam confundir o papel do cidadão e do consumidor, invariavelmente os tornando uma coisa só. Diante disso, Santos (1998) aponta para a grande falta de integração do ser humano ao papel de cidadão junto ao espaço o qual está inserido, condição essa que afeta milhões de brasileiros. Como solução, é defendido um "modelo cívico-territorial" que dá origem a um gerenciamento do espaço (natural ou não) de forma totalmente democrática, utilizando-se de ferramentas que visam à aplicação da justiça social; a partir disso cada indivíduo irá conquistar a sua cidadania.

Através dessa conquista, o conceito de cidadania é desvinculado do consumismo (que é o ópio do povo), gerando efeitos culturais positivos, 
fazendo com que os reais cidadãos passem a socializar a informação, o conhecimento, a educação e o consumo do espaço como um todo (assim como o que está contido nele) suprimindo e reduzindo todas as diferenças sociais e tirando cada indivíduo marginalizado do anonimato ou da cegueira social a qual ele estava previamente subjugado (SANTOS, 1998).

Em recente divulgação, a Organização Não Governamental (ONG) Internacional World Wide Fund for Nature (WWF) elaborou um estudo vinculado à Pegada Ecológica (que calcula, em hectares, a extensão de território que uma pessoa ou toda uma sociedade faz uso, em média, para se sustentar), denominado como "O dia da sobrecarga". Tal estudo consiste em identificar o dia do ano em que os habitantes do planeta Terra consumiram todos os recursos por ela disponibilizados durante o período de um ano, respeitando sua capacidade de carga e resiliência, e em 2013, esse marco foi atingido no dia 20 de agosto, ou seja, 133 dias antes do prazo que seria considerado ideal; em 2012, essa marca foi atingida no dia 22 de agosto, em 2003 no dia 22 de setembro e em 1993, 21 de Outubro. Segundo também a WWF, o planeta Terra já é deficitário, na relação produção e consumo de recursos, desde os anos 70 (WWF, 2014). Tendo este cenário Rodrigues (1992, p. 80) afirma que:

Esta velocidade de transformação tem-se manifestado também na transformação do conceito de renovabilidade de recursos naturais. Alguns recursos que até recentemente eram considerados "renováveis" [...], sofrem um processo irreversível de esgotamento, poluição, destruição, tornando-se hoje recursos "não renováveis". [...] Prevendo-se "esgotamento" de recursos e destruição da biodiversidade, não se procura alterar as formas de produção de mercadorias, mas sim de "guardar" alguns possíveis "recursos para um mercado "futuro"'.

E para despertar nos atores envolvidos um novo grau de consciência e entendimento do que ocorre globalmente, é fundamental o uso de ferramentas adequadas de educação.

A educação congrega valores morais e o tipo de sociedade em que cada indivíduo está inserido, apontando para a existência de etapas para se perceber a natureza, onde primeiramente, há a experiência imediata ou sensorial, seguida da categorização, interpretação e análise desta informação pela mente podendo resultar na geração das mais diversas respostas emocionais como medo, paz, felicidade, tristeza, apreensão e etc. Após este processo, pode-se ocorrer uma dimensão de valores, através do julgamento que, a partir de então, a dimensão científico-analítica poderá realizar-se por meio do estabelecimento de relações, da formulação de teorias e conceitos (SOULÉ, 1997). 


\section{Materiais e métodos}

\section{O local de estudo}

O estudo em questão se concentrou nas dependências do Clube de Campo "Alpha" (CCA), o qual é uma associação sem fins lucrativos, situado em uma cidade na Região de Sorocaba, interior do Estado de São Paulo.

\section{Metodologia}

A coleta de dados primários deu-se através de um roteiro semiestruturado junto aos funcionários do Clube de Campo Alpha (CCA). O roteiro foi dividido em 4 blocos, o primeiro visou adquirir informações socioeconômicas. O Bloco 2 procurou saber mais a respeito dos conhecimentos dos funcionários em relação ao Meio Ambiente (MA) e ao CCA; - Bloco 3 buscou saber a respeito dos conhecimentos dos entrevistados em relação às ações do CCA voltadas ao MA; e por final, o Bloco 4, teve por objetivo avaliar o conhecimento do entrevistado em relação ao Gestão de Resíduos Sólidos (GRS) executada pelo CCA.

Neste artigo, serão expostos e discutidos os dados referentes aos Blocos 1, 2 e 3. O bloco 4 receberá uma atenção separada em outro trabalho.

Para obter-se uma amostragem que contemplasse uma margem de erro de apenas $5 \%$ e um grau de confiabilidade de $95 \%$, usamos como base a quantidade de funcionários presentes no quadro da empresa no mês de Agosto de 2014, à época, composto por 217 profissionais, 5 estagiários e 5 jovens aprendizes (num total de 227), nos dando uma quantidade mínima de 143 colaboradores a serem entrevistados. Tal cálculo deu-se através da seguinte fórmula (SANTOS, 2014):

$$
n=\frac{N \cdot Z^{2} \cdot p \cdot(1-p)}{Z^{2} \cdot p \cdot(1-p)+e^{2} \cdot(N-1)}
$$

Onde: $\mathrm{n}=$ amostra calculada, $\mathrm{N}=$ população, $\mathrm{Z}$ = variável normal padronizada associada ao nível de confiança, $p=$ verdadeira probabilidade do evento e e = erro amostral.

No total foram entrevistados 150 colaboradores, no período de junho a outubro de 2014. A escolha da coleta de dados por meio de entrevistas deu-se pelo fato da dificuldade de alguns funcionários em compreender o teor do questionário, identificado no pré-teste, e a consequente dificuldade em respondê-lo, assim como também, por limitações na escrita por conta do baixo grau de escolaridade de muitos deles. 


\section{Caracterização dos Sujeitos}

Conforme anteriormente mencionado, foram entrevistados ao todo 150 funcionários do CCA, sendo eles: 143 contratados via Consolidação das Leis Trabalhistas (CLT), 5 contratados a partir de estágio e 2 contratados a partir do programa de jovem aprendiz.

Destes, 103 (68,67\%), são do gênero masculino e 47 (31,33\%), do gênero feminino, distribuindo-se nas seguintes faixas etárias: $35(23,33 \%)$ com 17 a 25 anos de idade, 87 (58\%) com 26 a 45 anos e 28 (18,66\%) com 46 a 64 anos. Levando em consideração o grau de escolaridade dos funcionários entrevistados, temos: $02(1,33 \%)$ analfabetos, $44(29,34 \%)$ que cursaram o ensino fundamental incompleto, $20(13,33 \%)$ com ensino fundamental completo, 69 (46\%) com ensino médio incompleto ou completo e $15(10 \%)$ com ensino superior completo ou incompleto.

Levando em consideração o estado civil dos entrevistados, temos o seguinte cenário: 46 (30,67\%) são solteiros, 94 (62,67\%) são casados, 9 (6\%) são divorciados e apenas $1(0,66 \%)$ é viúvo. Foi levantado também a quantidade de filhos sendo que, dos entrevistados $44(29,34 \%)$ não possuem filhos, $43(28,67 \%)$ possuem apenas 1 filho, 33 (22\%) possuem 2 filhos, 22 $(14,66 \%)$ possuem 3 filhos e 8 (5,33\%) possuem mais de 3 filhos.

A distribuição geográfica dos funcionários apontou para uma grande concentração dos mesmos no município de Araçoiaba da Serra, sendo que 119 $(79,33 \%)$ deles declararam residência no município supracitado; 18 (12\%); em Salto de Pirapora; 10 (6,66\%) em Sorocaba e 1 (0,67\%) em Capela do Alto, Votorantim e Piedade em cada um destes municípios.

Dentro da classificação das funções executadas pelos funcionários em suas atribuições diárias, $120(80 \%)$ estão ligados à área operacional, 19 $(12,67 \%)$ ligados à área administrativa e 11 (7,33\%) ligados à área técnica, sendo que $32(21,33 \%)$ dos colaboradores trabalham no CCA há até 1 ano, 42 (28\%) entre 1 ano a 3 anos e 11 meses, $24(16 \%)$ entre 4 a 7 anos e 52 $(34,67 \%)$ há mais de 7 anos, com $37(24,67 \%)$ exercendo a mesma função há até 1 ano, $50(33,33 \%)$ entre 1 ano a 3 anos e 11 meses, $32(21,33 \%), 32$ $(21,33 \%)$ entre 4 a 7 anos e $31(20,67 \%)$ há mais de 7 anos. Com isso podemos observar que a grande maioria dos funcionários do CCA entrevistados, possui uma maior estabilidade no emprego por conta de estar há pelo menos um ano trabalhando no local, o que dá, teoricamente, um maior contato e proximidade das ações e procedimentos (em suas mais variadas áreas de gestão) executados pelo CCA em sua rotina diária, com o objetivo de aperfeiçoar suas ações através de padrões estabelecidos.

Foi observado também que aproximadamente $82 \%$ dos funcionários habitam áreas consideradas rurais em seus municípios. 


\section{Apresentação e discussão dos resultados}

Abaixo, efetuamos a apresentação dos resultados obtidos através das entrevistas realizadas com os funcionários do CCA, a partir das perguntas presentes no roteiro dos Blocos 2 e 3, assim como a discussão dos mesmos, para o entendimento da percepção ambiental (PA) dos funcionários.

A primeira pergunta, bloco 2. O que você entende por meio ambiente (MA)? As respostas foram tabuladas e categorizadas em três blocos distintos, usando-se como base a proposta de Reigota (1995), em três diferentes vertentes, sendo a primeira delas, o meio ambiente é visto de forma mais próxima à natureza, dando maior ênfase somente aos aspectos naturais (de forma dissociada do homem); a segunda, com o meio ambiente sendo visto como o meio habitado, privilegiando a utilidade dos recursos para sobrevivência do homem, assim como provedor do meio e locais vividos (com uma visão mais antropocêntrica); e a terceira, com o meio ambiente sendo visto de maneira mais globalizante e até mesmo em escalas maiores (evidenciando as relações entre a natureza e a sociedade formando um único organismo que se interdepende). Os dados estão presentes na Tabela 1.

Tabela 1: Resposta pelo o que os colaboradores do CCA entendem por MA.

$$
\mathrm{n}=150
$$

\begin{tabular}{lcccccc}
\hline RESPOSTA & Analfabetos & $\begin{array}{c}\text { Fundamental } \\
\text { Incompleto }\end{array}$ & Fundamental & $\begin{array}{c}\text { Ensino } \\
\text { Médio }\end{array}$ & Superior & Total \\
\hline Meio Global & - & 2 & 1 & 6 & 4 & 13 \\
Meio Vivido & - & 3 & 3 & 9 & 11 & 26 \\
Meio Natural & - & 23 & 12 & 41 & 5 & 81 \\
Não soube definir/ & 2 & 17 & 4 & 17 & 0 & 40 \\
Resposta confusa & & & & & & \\
\hline
\end{tabular}

Claramente a definição do conceito de MA não é uníssona tanto no meio acadêmico quanto no educacional e tampouco no popular. Há claras divergências, diferenciando-se entre aspectos tecnológicos, políticos, culturais, sociais e até mesmo filosóficos, e o debate acerca do mesmo é amplo, denso e complexo. Tendo este cenário, podemos nos basear na definição do conceito de MA dada por Reigota (2009, p.36) que é:

Um lugar determinado e/ ou percebido onde estão em relação dinâmica e em constante interação os aspectos naturais e sociais. Essas relações acarretam processos de criação cultural e tecnológica e processos históricos e políticos de transformações da natureza e da sociedade. 
aprofundado acerca da singularidade de cada situação, e é também percebido, já que cada ator traça tais limites e fronteiras de acordo com as suas percepções e resultados de experiências do seu dia a dia dentro do seu conhecimento particular, individual e específico angariados neste mesmo espaço e tempo. As relações dinâmicas e interativas, por sua vez, apontam para uma constante mutação, fruto da dialética proveniente dos mais diversos grupos sociais e suas relações com o meio natural e construído, resultando em um processo de criação permanente, estabelecendo e caracterizando culturas em tempo e espaço específicos (com o recorte de tal espaço e tempo ficando a critério do dimensionamento do estudo e entendimento a ser feito).

Pode-se observar que a maioria dos entrevistados (50,6\%), enquadrou suas respostas na categoria Meio Natural, sendo o Meio Vivido a segunda opção $(16,3 \%)$ e posteriormente veio o Meio Global $(8,1 \%)$. Houve ainda, uma quantidade razoável de pessoas que não soube de forma alguma $(25,0 \%)$ buscar uma definição própria do conceito de MA, não sabendo responder ou até mesmo dando respostas confusas as quais não se enquadraram de forma alguma nas categorias supracitadas. Nesta tabela, o número total de respostas ultrapassa o número total de entrevistados, tendo em vista a ocorrência de casos os quais uma pessoa acabou dando mais de uma definição para o conceito.

Essa distribuição nas respostas nos faz observar que nem todos os atores envolvidos observam a mesma realidade; cada um a partir de sua perspectiva e pontos de vista, colhe os resultados pertinentes ao seu grau de conhecimento ou interesse, o que torna todo este processo dinâmico e singular, assim como a compreensão do espaço o qual está inserido e de seu meio de manifestação (TUAN, 1980).

Analisando as respostas de forma separada, levando em consideração o grau de escolaridade dos entrevistados, pode-se observar uma tendência na diminuição de pessoas as quais não souberam responder o que acredita ser ou definir o conceito de MA. Quanto maior o grau de escolaridade, menor foi a dificuldade na atribuição do significado ou conceito, e maior também a concentração de respostas já considerando o Meio Global e o Meio Vivido, em detrimento do Meio Natural.

Todos os dois (100\%) funcionários que se autodeclararam analfabetos não souberam definir o conceito. Já aqueles com ensino fundamental incompleto, 45 respostas no total (dentre 44 funcionários), teve a seguinte distribuição de respostas: $37,8 \%$ (17) não conseguiu definição, $51,2 \%$ (23) enquadrou suas respostas no Meio Natural, 6,6\% (3) no Meio Vivido e 4,4\% (2) no Meio Global; nos funcionários com ensino fundamental completo, 20 respostas no total (dentre 20 funcionários), tivemos: 20\% (4) não conseguiu definição, $60 \%$ (12) enquadrou suas respostas no Meio Natural, 15\% (3) no Meio Vivido e $5 \%$ (1) no Meio Global; nos funcionários com ensino médio, 73 respostas no total (dentre 69 funcionários), tivemos: $23,3 \%$ (17) não conseguiu definição, 56,2\% (41) enquadrou suas respostas no Meio Natural, 12,3\% (9) no Meio Vivido e 8,2 (6) no Meio Global; e finalmente, nos funcionários com ensino

revista brasileira educação ambiental 
superior, 20 respostas no total (dentre 15 funcionários), tivemos: 0\% (0) não conseguiu definição, 25\% (5) enquadrou suas respostas no Meio Natural, $55 \%$ (11) no Meio Vivido e $20 \%$ (4) no Meio Global.

A visão de Sauvé (1992) acaba complementando a visão de Reigota (1995), onde a partir de sua visão fenomenológica do discurso e das ações práticas de EA acaba identificando seis concepções paradigmáticas a respeito do MA (que serão abordadas de forma resumida), que em sua grande maioria vem sendo entendidas separadamente, ou no máximo em uma pequena combinação, sendo elas:

- Ambiente como a natureza... para ser apreciado, respeitado, preservado: Este é o ambiente original e "puro" do qual os seres humanos estão dissociados e no qual devem aprender a se relacionar para enriquecer a qualidade de "ser".

- Ambiente como um recurso... para ser gerenciado: É a nossa coletiva herança biofísica, que sustenta a qualidade de nossas vidas, em que este recurso limitado é deteriorado e degradado, o qual pode ser (mas não está sendo) gerenciado de forma equitativa e racional para o uso comum.

- Ambiente como um problema... para ser resolvido: É o nosso ambiente biofísico, o sistema de suporte da vida que está sendo ameaçado pela poluição e pela degradação, o qual devemos aprender a preservar e manter a sua qualidade.

- Ambiente como um lugar para se viver... para conhecer e aprender sobre, para planejar para, para cuidar de: É o nosso ambiente do cotidiano, na escola, nas casas, na vizinhança, no trabalho, no lazer. Este ambiente é caracterizado pelos seres humanos, nos seus aspectos socioculturais, tecnológicos e componentes históricos, sendo aquele o qual devemos aprender a apreciar e desenvolver o senso de pertencer a ele.

- Ambiente como a biosfera... onde devemos viver juntos, no futuro: Esse é o objeto da consciência planetária, o mundo de interdependência entre os seres vivos e inanimados, que clama pela solidariedade humana.

- Ambiente como projeto comunitário... onde somos envolvidos: É o ambiente da coletividade humana, o lugar dividido, o lugar político, o centro da análise crítica, o qual clama pela solidariedade, democracia e pelo envolvimento individual e coletivo para a participação e a evolução da comunidade.

Pode-se observar que, para cada representação particular, o foco pode ser enriquecido e melhor elaborado por diferentes outras percepções que se enquadrem em cada contexto, ou até mesmo pela combinação dos elementos característicos de um ou mais arquétipos que naturalmente se inter-relacionam e podem ser combinados de diversas formas, caminhos e ordem, já que são eminentemente complementares e se trabalhados em suas totalidades e em conjunto chegarão na concepção global e holística necessária para um melhor entendimento de cada indivíduo acerca do MA (SAUVÉ, 1997b). 
Durante as entrevistas foi bastante observado que os funcionários que optavam pela visão do Meio Natural, em relação ao conceito de MA, dificilmente se colocavam como parte integrante desse meio, dando respostas como, por exemplo: as árvores, os rios, os animais, não poluir as florestas e etc.... A visão dissociada de suas funções e ações como parte integrante e capaz de interferir na natureza, mostra que cada vez mais o homem tem se afastado dessa relação natural, de unidade e cooperação, e tem cada vez mais enxergado o Meio Natural como algo distante, alcançável, porém não fazendo mais tanta parte do seu cotidiano e de sua vida, ou seja, "dificilmente um ser humano contemporâneo se acha parte da natureza. Um dos princípios éticos da EA é desconstruir e ideia antropocêntrica do ser humano e reaproxima-lo da natureza" (REIGOTA 2009, p. 16).

Como aponta Dourado e Belizário (2012), é de suma importância e significado o papel desempenhado pelas sociedades civis (onde obviamente o CCA está inserido), na elaboração e aplicação de ações e atividades ligadas à EA (incluindo relações de consumo, as quais interferem diretamente na depredação do Meio Natural), e fazendo uso de práticas e ferramentas que impulsionem positivamente a informação de seus funcionários (que também são cidadãos), e que podem levar o conhecimento adquirido para outras localidades, desta forma, podemos buscar tal reaproximação do homem com a natureza, dando maior noção de corresponsabilidade em suas ações.

A segunda pergunta, presente no Bloco 2, buscou saber dos funcionários, quais ações práticas eles realizavam em seu dia a dia no CCA que os faziam acreditar estar ajudando o MA. Os dados coletados das respostas foram categorizados e estão expostos na Tabela 2, que segue abaixo.

Tabela 2: Resposta das ações práticas que cada funcionário realiza no CCA em que eles acreditam estar ajudando o MA.

$$
n=150
$$

\begin{tabular}{|c|c|c|c|c|c|c|}
\hline RESPOSTA & Analfabetos & $\begin{array}{c}\text { Fundamental } \\
\text { Incompleto }\end{array}$ & lamental & $\begin{array}{l}\text { Ensino } \\
\text { Médio }\end{array}$ & Superior & Total \\
\hline $\begin{array}{l}\text { Descarta o lixo de acordo com } \\
\text { a classificação da coleta } \\
\text { seletiva }\end{array}$ & - & 11 & 7 & 40 & 9 & 64 \\
\hline $\begin{array}{l}\text { Descartando lixo no lixo (sem } \\
\text { citar a coleta seletiva) }\end{array}$ & - & 4 & 10 & 17 & 1 & 32 \\
\hline $\begin{array}{l}\text { Economia de Recursos e reuso } \\
\text { de materiais }\end{array}$ & - & 4 & 3 & 15 & 5 & 27 \\
\hline $\begin{array}{l}\text { Não descartando produtos } \\
\text { nocivos em corpos d'água e } \\
\text { áreas verdes }\end{array}$ & - & 2 & - & - & - & 2 \\
\hline $\begin{array}{l}\text { Condicionou a resposta apenas } \\
\text { a suas funções profissionais }\end{array}$ & - & 14 & 5 & 16 & 3 & 38 \\
\hline $\begin{array}{l}\text { Não soube definir / Não } \\
\text { respondeu / Resposta confusa }\end{array}$ & 2 & 14 & 1 & 4 & 1 & 22 \\
\hline
\end{tabular}


Novamente a quantidade total de respostas dadas a esta pergunta ultrapassa o número total de 150 entrevistados, já que a mesma abre possibilidade para mais de uma resposta.

Dentre as ações, que de certa forma ajudam o MA, citadas pelos funcionários, podemos verificar que $64(42,7 \%)$ deles disseram procurar descartar o lixo corretamente de acordo com a classificação proposta na coleta seletiva; 32 (21,33\%) deles afirmaram que descartam o lixo no lixo, sem mencionar a coleta seletiva (esta resposta foi categorizada de forma separada, já que muitos funcionários foram claros na intenção de que se tratava da limpeza do local e manutenção do bom ambiente, e não em encaminhar os resíduos para as Cooperativas de catadores parceiras); 27 (18\%) deles afirmaram contribuir através da economia de recursos (água e energia elétrica) e até mesmo do reuso de materiais (usando folhas de rascunho para reimpressão ou copos descartáveis por mais de uma vez), e essa alternativa sofreu uma grande impulsionada, sendo lembrada mais vezes, de acordo com o agravamento da situação hídrica no Estado de São Paulo, em 2014; apenas $2(1,3 \%)$ dos funcionários afirmaram contribuir ao evitar descartar produtos nocivos (como restos de tinta ou óleo usado) em locais inapropriados (no solo ou em corpos d'água); e 22 (14,6\%) funcionários não souberam responder ou precisar alguma ação em que acreditavam estar ajudando o MA.

Um fato que chamou a atenção nesta questão foi a quantidade de funcionários os quais condicionaram suas práticas apenas às atividades executadas diariamente dentro de suas funções profissionais, somando 38 $(25,3 \%)$. Unindo aos já supracitados 22 funcionários que não souberam responder ou precisar alguma ação, temos um total de 60 (40\%) funcionários que acabaram ficando dentro de uma faixa abaixo do esperado, e em ambas as alternativas houve representantes de todos os graus de escolaridade, inclusive de nível médio e superior, mostrando que não é apenas um problema de formação escolar ou profissional, mas sim de reconhecimento e percepção do espaço a sua volta, assim como de dimensionamento do mesmo (aumento da escala do meio reconhecido e percebido).

Esse cenário reforça a necessidade de se buscar e aplicar atividades que trabalhem com diversos grupos, inclusive com graus de escolaridade distintos, e em diferentes dimensões de reconhecimento e percepção, já que não dependem apenas dos nossos sentidos ou órgãos sensoriais; vão muito mais além e profundamente em cada indivíduo, onde suas percepções e reconhecimentos são auto selecionados a partir dos elementos constituintes e que constituíram sua personalidade (resultados de experiência vividas, aspectos culturais, sociais, econômicos, políticos, e etc...), conforme Oliveira (1983, p. 48) coloca:

[...] não é mera sensação dada pelos órgãos sensoriais. Vemos, ouvimos, sentimos, enfim tudo aquilo que estimula os nossos sentidos. Mas percebemos somente o que a nossa mente atribui significado. A percepção é altamente seletiva Revbea, São Paulo, V. 11, № 1: 264-283, 2016. 
exploratória, antecipadora. Daí consideramos uma atividade perceptiva, que nos explora, seleciona, compara, antecipa tudo o que percebemos [...].

Os dados da Tabela 2 apontam, também, claramente para uma grande associação da preservação do MA com o problema do lixo, e principalmente com a sua destinação para a reciclagem, limitando a forma de atuação e colaboração dos atores na temática ambiental. Conceitos como "repensar", "reduzir" e "reutilizar", acabam sendo preteridos e muitas vezes nem considerados pelos atores como uma forma de participar ativa e cotidianamente, mesmo com pequenas ações.

Segundo Sato (2001), toda esta ênfase e atenção dada apenas ao terceiro "R" (reciclagem), em detrimento dos demais (redução e reutilização), que obviamente são mais importantes e fundamentais nos programas de EA, é prejudicial para aumentar a dimensão da percepção ambiental dos atores envolvidos.

A partir destas respostas podemos reforçar a evidência constatada na pergunta anterior, já que uma visão mais ampla e difundida de ações as quais podem ajudar o MA, de uma forma mais global e cobrindo uma maior gama de problemas e pontos a serem melhorados, acaba ficando restrita e limitada, 0 que gera a falta de uma visão holística da problemática ambiental, levando os atores a prioritariamente concentrar suas ações em apenas um ponto. Sabemos que o meio em que vivemos funciona em relações de cadeia, com ação, efeito e reação, com tudo intrinsecamente ligado (OLIVEIRA; MACHADO, 2004).

Outro ponto observado durante a entrevista é de que muitos dos funcionários dizem contribuir com a reciclagem, ao invés da coleta seletiva, fazendo uso e aplicações equivocadas do conceito, tendo em vista que os atores não efetuam a reciclagem propriamente dita, mas sim descartam 0 material adequadamente para envio à Cooperativa de catadores do entorno, que após segregação do material e agregação de valor, o encaminham até chegar de fato às usinas de reciclagem.

A terceira pergunta, esta por sua vez abrindo o Bloco 3, buscou saber, baseando-se no conhecimento e percepção de cada entrevistado, se conheciam alguma ação relacionada ao MA que fosse executada pelo Departamento de Sustentabilidade (DS) do CCA, e caso afirmativo, quais seriam essas ações. Os dados coletados das respostas foram categorizados e estão expostos na Tabela 3, que segue abaixo. 
Tabela 3: Resposta dos funcionários das ações por eles conhecidas executadas pelo CCA, através do Departamento de Sustentabilidade (DS), que são relacionadas ao MA.

$n=150$

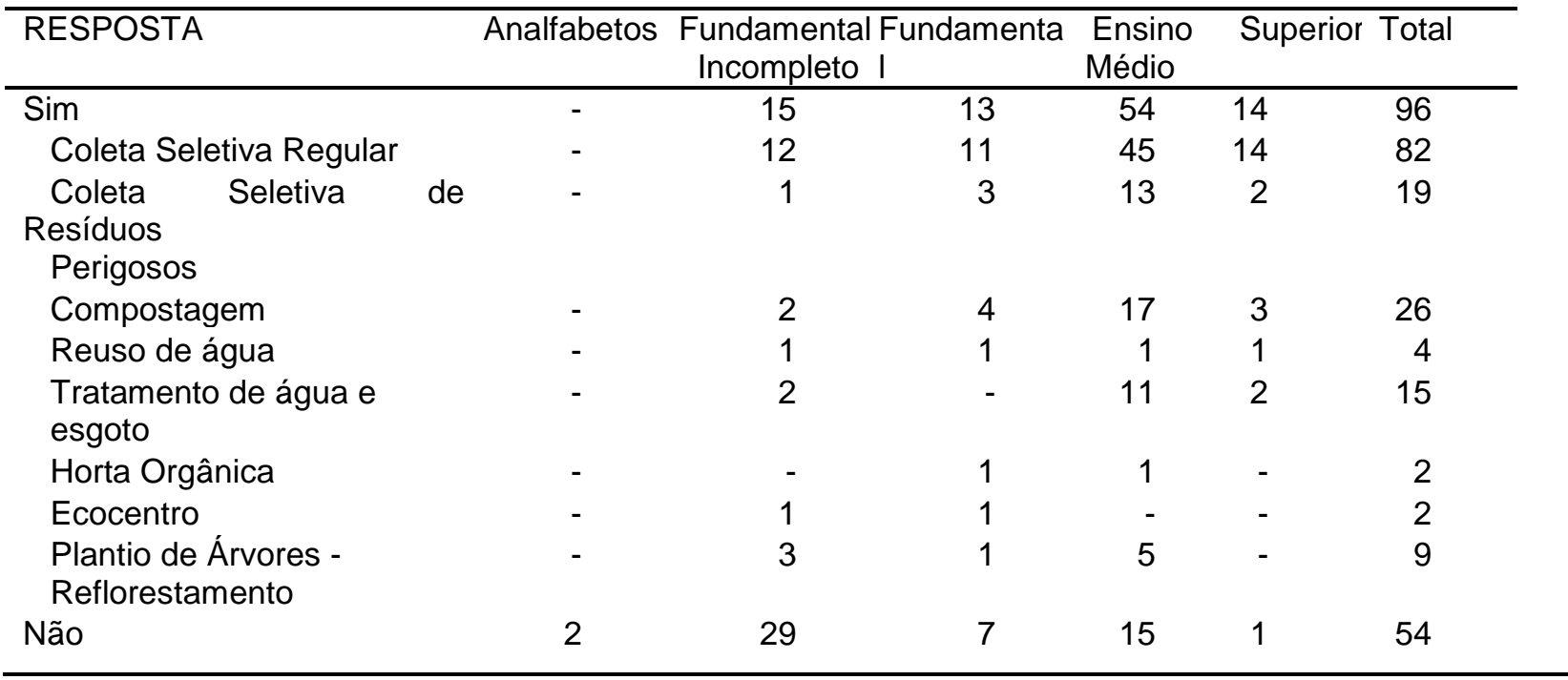

De todos os funcionários entrevistados, 96 (64\%) afirmaram conhecer alguma ação relacionada ao MA, executada através do DS do CCA, e 54 (36\%) afirmaram desconhecer.

Novamente podemos observar a presença de todos os graus de escolaridade que responderam não conhecer nenhuma ação relacionada ao MA executada pelo DS do CCA, assim como foi inversamente proporcional em cada grau de escolaridade, ou seja, quanto menor o grau de escolaridade, maior a proporção de funcionários que desconhecia alguma dessas atividades, sendo $100 \%$ dos analfabetos, $65,9 \%$ com nível de ensino fundamental incompleto, $35 \%$ com nível de ensino fundamental completo, $21,7 \%$ com nível de ensino médio e 6,6\% com nível superior.

Para aqueles que afirmaram conhecer ao menos alguma atividade, suas respostas foram categorizadas, e de modo geral, foram distribuídas da seguinte forma, decrescentemente: $82(54,6 \%)$ citaram a Coleta Seletiva Regular (apenas de materiais recicláveis básicos e não recicláveis), 26 (17,3\%) citaram a Compostagem, $19(12,6 \%)$ citaram a Coleta Seletiva de Resíduos Perigosos (pilhas e baterias, lâmpadas fluorescentes e equipamentos eletrônicos de pequeno, médio e grande porte), $15(10 \%)$ citaram o tratamento de água e esgoto, $9(6 \%)$ citaram o plantio de árvores e ações de reflorestamento, 4 $(2,6 \%)$ citaram o reuso de água, $2(1,3 \%)$ citaram a horta orgânica e, finalmente, outros $2(1,3 \%)$ citaram o Ecocentro (local onde se concentra diversas atividades e ações relacionadas à sustentabilidade).

Com esses resultados apresentados, observa-se o mesmo padrão diagnosticado e obtido nas respostas da segunda pergunta (dados presentes na Tabela 2), com forte associação do DS com a coleta seletiva de resíduos por parte daqueles que alegaram conhecer ao menos uma atividade do departamento supracitado, assim como o erro conceitual por parte dos Revbea, São Paulo, V. 11, № 1: 264-283, 2016. 
entrevistados ao usar o termo reciclagem, como coleta seletiva. Outras atividades de suma importância foram pouco lembradas, como o tratamento de efluentes, já que o CCA, possui poços artesianos, sistemas de tratamento e distribuição próprios, além também de coletar e tratar $100 \%$ do esgoto gerado em suas dependências. Mesmo com a grave crise hídrica enfrentada pelo Estado de São Paulo no ano de 2014, questões relativas à água, nesta questão, foram pouco lembradas.

Loureiro (2003), nos mostra que isso ocorre em vários locais onde é adotada uma EA de forma conservadora, e porque não dizer clichê, que coloca o lixo sempre como principal vilão, o qual deve ser constantemente combatido através da coleta seletiva, não aprofundando o debate e as discussões voltadas para a relação produção-consumo-cultura.

Além dos aspectos citados acima, a ausência de menção às atividades e ações relacionadas à EA é um aspecto a ser observado, cabendo futuramente ao CCA, organizar ações pontuais que possam dar maior preenchimento a este assunto. A EA é de extrema importância na busca por soluções para a elevação do grau de consciência e interação dos seres no meio, e deve ser trabalhada em sua totalidade, conforme proposto por Sauvé (1997a), com a Educação sobre o MA, no MA, e também, para o MA.

Para Whyte (1978), esse cenário caracteriza a necessidade de se elaborar estudos acerca das diferentes populações que interagem com o MA, sendo que tais estudos têm como claros objetivos aumentar em todos os atores (dentro de suas mais variadas singularidades e individualidades) a compreensão dos elementos e princípios das diferentes percepções do ambiente; deve ajudar também na manutenção e preservação das percepções e sistemas de conhecimento do MA (muito dos quais estão em vias aceleradas de desaparecimento e provável esquecimento); deve buscar encorajar as ações e participações nas mais variadas esferas e dimensões (localmente e até, porque não, globalmente) de toda a comunidade e de todos os atores envolvidos no planejamento e desenvolvimento destas ações, os colocando como fundamentais em todo o processo a fim de mostrar-lhes sua importância como agentes transformadores do meio; deve ainda contribuir para o uso mais consciente e racional de todos os recursos disponíveis, e ainda a serem dispostos, em toda a biosfera terrestre (e, quem sabe ainda, devido aos avanços tecnológicos, de outros locais), otimizando e maximizando seu uso dentro de seus potenciais totais, com acesso mais justo e igualitário por todos os seres vivos (de todas as espécies) que coabitam este planeta; e finalmente deve agir enquanto instrumento educativo, ou seja, fazer uso de seus conhecimentos teóricos, e também fruto de suas experiências, com o objetivo de passa-los adiante para os demais diversos atores envolvidos, socializando tais conhecimentos, com o objetivo de melhorar o homem, que trabalhará, reconhecerá e perceberá o MA de outra forma e em uma dimensão aumentada, e não mais restrita e limitada.

A quarta pergunta aberta, o Bloco 3, buscou saber dos colaboradores entrevistados se os mesmos acreditavam que as ações executadas pelo CCA

revista brasileira educação ambiental 
relacionadas ao MA através do DS eram suficientes, e em caso negativo, perguntou-se adicionalmente quais outras ações poderiam ser feitas. As respostas adicionais foram categorizadas e estão descritas logo a seguir, na Tabela 4.

Tabela 4: Respostas dos colaboradores do CCA se acreditam que as ações relacionadas ao MA executadas pelo CCA através do DS são suficientes, e em caso de resposta negativa, qual ação adicional poderia ser tomada.

\begin{tabular}{|c|c|c|c|c|c|c|}
\hline RESPOSTA & Analfabetos & $\begin{array}{c}\text { Fundamental } \\
\text { Incompleto }\end{array}$ & Fundamental & $\begin{array}{l}\text { Ensino } \\
\text { Médio }\end{array}$ & Superior & Total \\
\hline $\operatorname{Sim}$ & 1 & 31 & 10 & 46 & 10 & 98 \\
\hline Não & - & 12 & 8 & 16 & 5 & 41 \\
\hline $\begin{array}{l}\text { Ações voltadas para EA dos } \\
\text { colaboradores }\end{array}$ & - & 2 & - & 4 & 2 & 8 \\
\hline $\begin{array}{l}\text { Mais soluções para a questãı } \\
\text { dos resíduos sólidos }\end{array}$ & - & - & 1 & 2 & 1 & 4 \\
\hline $\begin{array}{l}\text { Necessita de maior } \\
\text { colaboração dos atores } \\
\text { envolvidos }\end{array}$ & - & 2 & 1 & 2 & - & 5 \\
\hline $\begin{array}{l}\text { Investir em fontes } \\
\text { renováveis } \\
\text { de energia }\end{array}$ & - & - & 1 & - & - & 1 \\
\hline Mais plantio de árvores & - & - & 1 & - & - & 1 \\
\hline $\begin{array}{l}\text { Ações voltadas para } \\
\text { reaproveitamento de água }\end{array}$ & - & 1 & 1 & - & 2 & 4 \\
\hline $\begin{array}{l}\text { Otimizar a logística dos } \\
\text { veículos operacionais }\end{array}$ & - & - & - & 1 & - & 1 \\
\hline Não sabe / Não quis opinar & 1 & 1 & 2 & 7 & - & 11 \\
\hline
\end{tabular}

Do total de entrevistados $98(65,4 \%)$ acreditam que as atividades relacionadas ao MA pelo CCA através do DS são sim suficientes, ao passo que $41(27,3 \%)$ acreditam não serem suficientes. Já $11(7,3 \%)$ dos colaboradores entrevistados não souberam responder à pergunta ou não quiseram opinar.

$\mathrm{Na}$ era atual, considerada a da tecnologia e informação, as grandes distâncias têm sido cada vez mais suprimidas, assim como o isolamento de indivíduos e populações, consolidando cada vez mais o processo de globalização, que para Santos (2000), a globalização como período possui as suas características variáveis mostrando-se presente e instalando-se em todos os lugares, influenciando a tudo, de forma direta ou indireta, e como crise, as mesmas características variáveis que constroem e constituem tal sistema estão constantemente entrando em choque, exigindo definições e arranjos atualizados (e faço eu aqui uma analogia aos softwares de computadores), onde diversos fatores ocorrem simultaneamente e em conjunto, realizando-se com muita força em toda a parte, saindo da concepção, limitação e isolamento de determinadas regiões, países ou até mesmo continentes, como outrora ocorriam em tempos passados, em que esses diversos fatores, se unem e se interligam, formando um sistema cada vez maior e mais complexo e de infindáveis variáveis.

Revbea, São Paulo, V. 11, № 1: 264-283, 2016. 
E para Keohane e Nye (2000) um dos assuntos resultantes deste processo complexo de globalização é a questão ambiental, sendo sem sombra de dúvidas alguma, um dos que possuem a maior importância, onde a variável ambiental emergiu como tema das relações internacionais contemporâneas, e que nos dias de hoje vem ganhando destaque como uma das temáticas que melhor exemplificam esta interdependência global de tamanha dimensão e complexidade.

E como aponta Dourado e Belizário (2012), em vista deste cenário, começa-se a haver a disseminação e multiplicação de práticas individuais e coletivas que buscam soluções dentro da complexa problemática ambiental, com maior alcance e visibilidade do termo "sociedade sustentável", e como pudemos observar, assim como percebido pela maioria dos colabores entrevistados , o CCA é um desses locais em que há uma manifestação de práticas coletivas com o objetivo (de ao menos servir de exemplo) de melhorar o panorama atual o qual experimentamos dentro da temática ambiental. Ainda de acordo com Dourado e Belizário (2012, p.29), tais práticas individuais e coletivas devem ser conscientes, bem informadas e realmente preocupadas com a temática ambiental onde "Ampliam-se os atores cujas ações passam a fazer parte de um repertório compartilhado por aqueles que veem na mudança de atitudes e escolhas a possibilidade de interferir na qualidade do MA", e ao ampliar o universo de atores engajados em ações que visam realmente contribuir na melhoria da qualidade do MA como um todo, amplia-se também a dimensão do espaço determinado e percebido, não apenas do MA, mas também dos processos articulados e intrínsecos à nossa sociedade de consumo e produção atual.

Ao fazermos uma análise adicional dos dados presentes na Tabela 4, podemos evidenciar que dos $41(27,3 \%$ de 150$)$ colaboradores entrevistados que afirmaram ser insuficientes as ações relacionadas ao MA, executadas pelo CCA através do DS, apenas $19(46,3 \%$ de 41$)$, ou seja, menos da metade, buscaram contribuir de forma mais crítica e com alguma sugestão do que pode ser feito para melhorar o cenário por eles percebido. As sugestões efetuadas foram categorizadas e distribuídas da seguinte forma: 8 (19,5\% de 41) acreditam que deve haver mais ações voltadas para a EA dos colaboradores; 5 $(12,2 \%$ de 41$)$ acreditam que o diferencial pode ser feito apenas com ações (mudanças de hábitos ou novas formas de condutas simples e voluntárias) diferenciadas dos demais colaboradores envolvidos; 4 (9,7\% de 41$)$ afirmaram que se necessita mais ações voltadas à solução do problema dos resíduos sólidos; $4(9,7 \%$ de 41$)$ citaram a necessidade por mais ações voltadas para o reaproveitamento de água; 1 (2,4\% de 41$)$ citou uma maior necessidade em investimentos relacionados a fontes renováveis de energia; 1 (2,4\% de 41$)$ citou mais ações envolvendo um maior plantio de árvores; e finalmente, 1 $(2,4 \%$ de 41$)$ sugeriu a elaboração de ações que otimizem a logística dos veículos operacionais do CCA.

Observa-se aí a necessidade de se buscar alternativas para a inclusão dos atores em ações que tenham como tema e objetivo principal, a

revista brasileira educação ambiental 
inclusão e participação dos mesmos nas atividades e discussões acerca de todos os desafios e problemáticas que envolvem a temática ambiental. Apesar do CCA já possuir atividades diversificadas relacionadas à temática ambiental (principalmente no tocante aos resíduos sólidos), é muito difícil chegar em um modelo com $100 \%$ de desempenho e eficácia, assim como manter constantemente uma alta taxa de funcionalidade deste sistema, e para isso, uma busca constante por novas ideias, soluções e procedimentos é sempre bem-vinda e mais do que necessária, assim como a participação dos mais variados atores incluídos no processo

Uma das principais ferramentas que pode, de fato, propiciar e incentivar tal participação mais próxima e ativa dos colaboradores, é a EA, com ações específicas e elaboradas levando em consideração a particularidade do local. $O$ fato de a EA ter sido a mais lembrada (apesar da pouca quantidade mencionada nas sugestões), aponta para sua importância como ferramenta para a mudança de postura e comportamento dos atores, e segundo Dourado e Belizário (2012, p. 24), a EA, como pedagogia da complexidade, busca o autoconhecimento do ser humano, com o objetivo de ao se conhecer, conhecer o outro e o meio que o cerca, com o homem "[...] compreendendo a complexidade da Vida, e será delineada a partir dos sonhos de cada pessoa e grupo social e do diálogo entre todos na construção de sociedades sustentáveis". Deste ponto de vista, gera um pensamento menos individualista, buscando uma sociedade que pense mais coletiva (não só relativo aos seres humanos), mas também considerando todas as formas de vida, e o meio o qual habitamos.

Dessa forma, podemos conseguir elementos para ao menos diminuir a quantidade daqueles colaboradores que, apesar de acharem as ações do CCA relacionadas ao MA, executadas através do DS insuficientes, acabaram não especificando nenhuma ação a qual, através da percepção e determinação deles, poderia de alguma forma melhorar os procedimentos executados pelo CCA.

\section{Conclusão}

Pôde-se diagnosticar que há uma maior necessidade de se promover atividades relacionadas à $E A$, que trabalhem mais 0 aspecto humano, mostrando ao indivíduo o seu poder de mudança e transformação no MA em que está inserido, já que foi observada uma predominância de ações pontuais e não contínuas nesse aspecto. O estímulo a essa nova percepção e a introdução de novas dimensões presentes na temática ambiental irão alçar o Programa de Sustentabilidade e de GRS do CCA para outro patamar, mostrando as inter-relações de tudo o que nos cerca, formando o todo, chegando aí, em uma visão global e de unidade.

Ficou claro no estudo efetuado, que a mudança da PA se faz mais do que necessária nos mais diversos atores sociais, respeitando suas posições e individualidades. O estudo apontou que o grau de escolaridade interfere 
apenas no campo teórico do conhecimento, facilitando a identificação, discernimento e definição de conceitos por conta dos atores entrevistados que possuem graus de instrução acadêmica mais alto, contudo, não foi de forma alguma fator determinante para o desejo de atuação e engajamento deles nas questões ambientais, inclusive na manifestação de ações práticas em suas condutas diárias para a mudança do paradigma ambiental enfrentado pela humanidade. Restringir a temática ambiental ao campo teórico e educacional apenas, é limitar a compreensão e atuação de todos os atores sociais, que precisam enxergar que o conhecimento deve ser aplicado. O uso prático deste conhecimento, crescente e contínuo, principalmente por conta dos avanços intelectuais e tecnológicos alcançados pela humanidade, irão sobrepujar o status quo e o senso comum atual, que ainda limitam os graus de percepção, determinação e atuação ambiental dos atores sociais.

A premente necessidade de se aliar o conhecimento teórico ao prático, de uma forma inclusiva e respeitosa entre todos esses atores, mostra-se como o caminho mais tangível para se reverter a crescente depredação do nosso ambiente como um todo. Não se deve restringir este conhecimento apenas ao meio limitado e reduzido ao qual é percebido e determinado pela falta de conhecimento e de consciência de todo o problema; deve-se visualizar e conhecer todos os fatores que se acumulam e compõem tal problema, deste modo, suprime-se a tendência pós-moderna de aplicação do reducionismo nas diversas áreas do conhecimento e também de todos os processos que regem as relações pessoais, culturais, sociais, políticas, econômicas, físicas, planetárias e etc...

O presente estudo nos mostrou que o CCA não pode limitar suas condutas e práticas ao estágio em que está, ou seja, deve-se buscar sempre mais, e o melhor caminho para o alcance do objetivo traçado, é o da Ação de todos os envolvidos a partir do reconhecimento do seu papel no Todo e a consciência do que deve ser feito, procurando chegar o máximo possível próximo do objetivo, que é servir $100 \%$ como modelo para demais localidades e atores. O papel do CCA é de extrema importância para a região, pois através de suas ações, pôde e pode minimizar ainda mais os problemas causados pela ausência e omissão do poder público ao aplicar ferramentas e métodos práticos e teóricos de GRS, e também de inclusão, para aqueles atores que se sentem isolados ou sem oportunidade de expressão e contribuição.

A temática ambiental e as relações humanas são complexas, contudo, um alto grau de compreensão e respeito pelo MA, por todas as formas de vida (da menor a maior) e pelo Planeta que nos serve de casa, é básico e fundamental para a mudança do paradigma que hoje enfrentamos, e que muitos indivíduos não encontram saída para sua solução, e novamente ressaltando o presente estudo, essas soluções podem estar (ou ao menos serem testadas) no meio em que vivemos e/ou atuamos. 


\section{Referências}

BAUMAN, Z. Vida para consumo. Rio de Janeiro: Zahar, 2008.

DOURADO, J.; BELIZÁRIO, F. (org.). Reflexão e Práticas em Educação Ambiental: Discutindo o Consumo e a Geração de Resíduos. São Paulo: Oficina de Textos, 2012.

GONÇALVES, C.W.P. Geografia Política e Desenvolvimento Sustentável. Terra Livre, São Paulo, no 11-12, 1996, p. 9-76.

GUERRA, S. Resíduos Sólidos. Rio de Janeiro: Forense, 2012.

KEOHANE, R.; NYE, J. Globalization. What's new? Waht's not? (And so what?). Foreign Policy. Spring, 2000, p. 106-116.

LOUREIRO, C.F.B. Premissas Teóricas para uma EA Transformadora. Ambiente e Educação, Rio Grande, vol. 08, n²1, 2003, p. 37-54.

OLIVEIRA, L de. O lixo urbano: um problema da percepção Ambiental. In: VII SIMPÓSIO ANUAL DA ACIESP,1983, São Paulo-SP, Anais...São Paulo-SP: Academia de Ciências do Estado de São Paulo, 1983, p. 48-56

OLIVEIRA, L.; MACHADO, L.M.C.P. Percepção, cognição, dimensão ambiental e desenvolvimento com sustentabilidade. In: VITTE, A.C; GUERRA, A.J.T. Reflexões sobre a Geografia física no Brasil. Rio de Janeiro: Bertrand Brasil, 2004, p. 129-152.

REIGOTA, M. Meio ambiente e representação social. São Paulo: Cortez, 1995. (Coleção Questões de Nossa Época)

REIGOTA, M. O que é Educação Ambiental. $2^{a}$ ed. São Paulo: Brasiliense, 2009 (Coleção Primeiros Passos)

RODRIGUES, A.M. Espaço, meio ambiente e desenvolvimento: Releitura do território. Terra Livre, São Paulo, n 11-12, 1996, p. 77-90.

SANTOS, G.E.O. Cálculo amostral: calculadora on-line. 2014. Disponível em: $<$ http://www.calculoamostral.vai.la>. Acesso em: 20/03/2014.

SANTOS, M. Espaço e Método. São Paulo: Nobel, 1985.

SANTOS, M. O espaço do cidadão. 4. ed. São Paulo: Nobel, 1998.

SANTOS, M. Por uma outra globalização: do pensamento único à consciência universal. São Paulo: Record, 2000.

SATO, M. Debatendo os desafios da Educação Ambiental. Anais do I Congresso de Educação Ambiental Pró Mar de Dentro, 2001, Rio Grande, Rio Grande, Programa de Pós-Graduação Mestrado em Educação Ambiental/FURG/ Pró Mar de Dentro, 17 a 21 maio, 2001, p.1-11.

SAUVÉ, L. Éléments d'une théorie du design pédagógique en éducation relative à l'environnement, Thèse de doctoral, Université du Québec à Montréal, 1992. 
SAUVÉ, L. Pour une éducation relative à l'environnement. 2e éd. Montréal: Guérin, 1997a.

SAUVÉ, L. EA e desenvolvimento sustentável: uma análise complexa. Revista do Programa de Pós-graduação em Educação da UFMT, Cuiabá, v. 6, n.10, jul/dez, 1997b, p. 72-103.

SOULÉ, M.E. Mente na biosfera: mente da biosfera. In: WILSON, E.O. Biodiversidade. Rio de Janeiro: Nova Fronteira, 1997, p. 593-598.

TUAN, Yi-Fu. Topofilia: um estudo da percepção, atitudes e valores do meio ambiente. São Paulo: Difel, 1980.

WHYTE, A.V.T. La perception de l'environment: lignes directrices méthodologiques pour les études sur le terrain. Paris: UNESCO, 1978.

WORLD WILDLIFE FUND. Alerta Vermelho: Em 20 de agosto, humanidade excedeu orçamento da Terra para 2013. WWF, 20 de agosto de 2013. Disponível em:

$<$ <ttp://www.wwf.org.br/informacoes/noticias meio ambiente e natureza/?359 02/Alerta-Vermelho>. Acesso em 24/08/2014. 